Int. J. Electrochem. Sci., 15 (2020) 2039 - 2051

International Journal of

ELECTROCHEMICAL

SCIENCE

$\underline{\text { Www.electrochemsci.org }}$

\title{
Cobalt and Nitrogen Co-doped Porous Carbon Spheres as Efficient Oxygen Reduction Electrocatalysts
}

\author{
Hanzeng Zou ${ }^{1}$, Zhaoyan Chen ${ }^{1}$, Xia Xiong ${ }^{1}$, Yueyang Sun ${ }^{1}$, Supeng Pei ${ }^{1, *}$, Yongming Zhang ${ }^{2,3}$ \\ ${ }^{1}$ School of Chemical and Environmental Engineering, Shanghai Institute of Technology, Shanghai \\ 201418, China. \\ ${ }^{2}$ School of Chemistry and Chemical Engineering, Shanghai Jiao Tong University, Shanghai 200240, \\ China. \\ ${ }^{3}$ State Key Laboratory of Fluorinated Functional Membrane Materials, China. \\ "E-mail: peisupeng@126.com
}

doi: $10.20964 / 2020.03 .52$

Received: 6 October 2019 / Accepted: 18 December 2019 / Published: 10 February 2020

In this paper, cobalt and nitrogen co-doped carbon sphere catalysts were synthesized by two methods, electrospinning and grinding. The two kinds of $\mathrm{Co}, \mathrm{N}$ co-doped carbon sphere catalysts were compared in a system. According to the results, Co-N-C-37.5 catalyst has a better oxygen reduction reaction (ORR) performance and a more spherical shape than the other catalysts. Additionally, it has the largest specific surface area of all tested electrocatalysts. For the electrochemical activity, the onset potential ( $E_{\text {onset }}$ ) of Co-N-C-37.5 is $0.979 \mathrm{~V}$, which is better than that of the commercial Pt/C catalyst $(0.967 \mathrm{~V})$. The half-wave potential $\left(\mathrm{E}_{1 / 2}\right)$ of Co-N-C-37.5 is $0.780 \mathrm{~V}$, which is slightly lower than that of the commercial Pt/C $(0.797 \mathrm{~V})$. After $10,000 \mathrm{~s}$ of durability testing, $88 \%$ of current is retained with Co-N$\mathrm{C}-37.5$, which is better than that of commercial Pt/C (83\%). In addition, the methanol tolerance of Co$\mathrm{N}-\mathrm{C}-37.5$ is better than that of the commercial Pt/C. The current density percentage of Co-N-C-37.5 has no distinct decrease after the addition of methanol at $500 \mathrm{~s}$. However, the commercial $\mathrm{Pt} / \mathrm{C}$ decreases sharply. Therefore, this study provides a facile way to produce $\mathrm{Co}, \mathrm{N}$ co-doped carbon sphere catalysts with good catalytic performance for the ORR.

Keywords: Electrospinning; Co, N co-doped; Carbon sphere; Oxygen reduction reaction

\section{FULL TEXT}

(C) 2020 The Authors. Published by ESG (www.electrochemsci.org). This article is an open access article distributed under the terms and conditions of the Creative Commons Attribution license (http://creativecommons.org/licenses/by/4.0/). 